\title{
Comparison of a Novel Lycra Endotracheal Tube Cuff to Standard Polyvinyl Chloride Cuff and Polyurethane Cuff for Fluid Leak Prevention
}

\author{
Theodor Kolobow MD, Massimo Cressoni MD, Myra Epp MSE, Ivan Corti DVM, \\ Paolo Cadringher MSE, and Alberto Zanella MD
}

\begin{abstract}
BACKGROUND: A high-volume low-pressure endotracheal tube (ETT) cuff forms folds along its contact with the trachea, allowing mucus leakage into the lungs. We developed a thin-walled ETT cuff made of Lycra polyurethane. METHODS: In vitro, we tested 6 of each of the new prototype Lycra cuff, the Mallinkrodt Hi-Lo ETT (polyvinyl chloride cuff), and the Kimberly-Clark Microcuff ETT (polyurethane cuff), for leakage, in an acrylic mock trachea (inner diameter 20-mm), with a cuff inflation pressure of $20 \mathrm{~cm} \mathrm{H} \mathrm{H}_{2} \mathrm{O}$. We poured $15 \mathrm{~mL}$ of methylene-blue colored water into the acrylic tube above the cuff and observed for leakage for 24 hours. RESULTS: The Lycra cuffs had no folds upon inflation in the mock trachea and completely prevented fluid leakage for 24 hours $(P<.001$ vs the Hi-Lo and the Microcuff $)$. The average leakage past the Hi-Lo was $1,182 \pm 1,321 \mathrm{~mL} / \mathrm{h}$. The average leakage past the Microcuff was $1.2 \pm 0.4 \mathrm{~mL} / \mathrm{h}(P<.001$ vs the Hi-Lo). CONCLUSIONS: Our Lycra cuff provided complete tracheal sealing in vitro. Key words: endotracheal tube; cuff; ventilator; mechanical ventilation; ventilator-associated pneumonia. [Respir Care 2011;56(8):10951099. (C) 2011 Daedalus Enterprises]
\end{abstract}

\section{Introduction}

The cuffs of currently available endotracheal tubes (ETTs) are made of polyvinyl chloride (PVC). Such cuffs

\footnotetext{
Dr Kolobow, Ms Epp, and Dr Corti are affiliated with the Section of Pulmonary and Cardiac Assist Devices, Pulmonary and Critical Care Medicine Branch, National Heart, Lung, and Blood Institute, National Institutes of Health, Bethesda, Maryland. Dr Cressoni and Mr Cadringher are affiliated with the Istituto di Anestesiologia e Rianimazione, Fondazione Istituto di Ricovero e Cura a Carattere Scientifico, Ospedale Maggiore Policlinico Mangiagalli Regina Elena di Milano, Milan, Italy. Dr Zanella is affiliated with the Department of Experimental Medicine, University of Milan-Bicocca, Monza, Italy.
}

Dr Cressoni presented a version of this paper at the International Symposium on Intensive Care and Emergency Medicine, held March 24-27, 2009, in Brussels, Belgium.

Correspondence: Massimo Cressoni MD, Istituto di Anestesiologia e Rianimazione, Fondazione Istituto di Ricovero e Cura a Carattere Scientifico, Ospedale Maggiore Policlinico, Mangiagalli, Regina Elena di Milano, Via Francesco Sforza, 35, 20122 Milan, Italy. E-mail: mcressoni@hotmail.com.

DOI: $10.4187 /$ respcare.01099 form an inflatable oblong cuff larger than the average diameter of the trachea, to block mucus flow into the lungs, and to prevent air leakage. Natural rubber latex ETT cuffs are unsuitable for long-term use, ${ }^{1}$ and the PVC cuff also has limitations. PVC has limited stretch upon inflation, so the cuff diameter needs to be larger than the trachea, and the cuff therefore forms folds along its contact with the trachea, ${ }^{2}$ which allow passage of pathogen-colonized mucus into the lungs, with a consequent increased risk of pneumonia.

See the Related Editorial on Page 1213

Recently marketed ETT cuffs made of very thin polyurethane (eg, SealGuard, Mallinckrodt/Covidien, Boulder, Colorado) can overcome some of the constraints of previous-generation PVC ETT cuffs. The very thin cuff wall ${ }^{3}$ forms smaller folds and thus allows less leakage. Mucus leakage past the cuff is a clinically important risk $^{4}$ that could probably be prevented with a very thin cuff made of a highly distensible elastomer. 


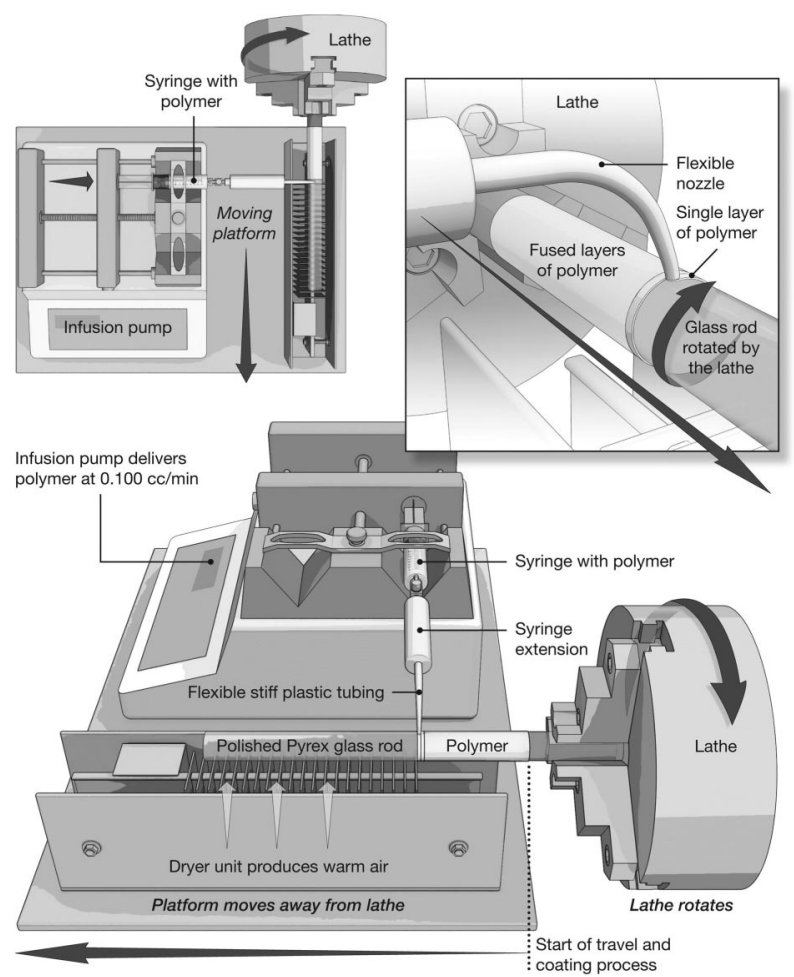

Fig. 1. Our method of fabricating a Lycra endotracheal tube cuff.

Some 20 years ago we developed technology to fabricate thin-walled arterial/venous catheters ${ }^{5}$ and thin-walled ETTs with Lycra polyurethane, dissolved in N,N-dimethylacetamide. ${ }^{6}$ Briefly, this entails using a small-gear pump to pump dissolved polyurethane solution onto a steel mandrel rotated by a lathe. The first layer is of polyurethane. After the solvent evaporates we apply a layer of nitinol (nickel/titanium) shape-memory wire for overall strength, then we apply another layer of polyurethane and dry the catheter overnight in a drying oven.

It seemed reasonable to apply this technology (without the wire reinforcement) to the fabrication of a prototype, highly elastic, ultra-thin-walled spherical or cylindrical ETT cuff. The aim of our experiment was to determine, with a static bench model of the trachea, if our Lycra ETT cuff prevents fluid leakage.

\section{Methods}

This study was performed at the National Institutes of Health, Bethesda, Maryland, and funded by the intramural research program of the National Heart, Lung, and Blood Institute.

Figure 1 shows the essentials of the manufacturing process. Onto a lathe we mounted a highly polished, straight, Pyrex glass rod of the diameter of the chosen ETT cuff $(18 \mathrm{~mm})$. The Lycra solution was $10 \%$ solids in N-N- dimethylacetamide, and was filtered before use. It was our goal to fabricate an ultra-thin-walled, cylindrical ETT cuff. For enhanced quality, we applied 2 coats of Lycra, rather than just one thick first coat, to allow for more rapid and uniform drying of the first coat, followed by a second coat of $10 \%$ Lycra, thus assuring absence of pinholes.

After 24 hours of drying in an oven at $60^{\circ} \mathrm{C}$, the cuff was removed from the glass mandrel and mounted on a standard, commercially available (Mallinckrodt) ETT, from which we had carefully removed the PVC cuff. We secured the Lycra cuff to the ETT with cotton/polyester yarn. We used no adhesives because the Lycra cuff might be weakened by the components of an adhesive. We tested each Lycra cuff for pinholes by inflating the cuff and immersing it under water.

\section{In Vitro Studies}

We evaluated the performance of 6 of each of the Lycra ETT cuffs, the $(8 \mathrm{~mm}$ inner-diameter $)$ Hi-Lo ETT (Mallinckrodt/Covidien, Boulder, Colorado), which has a PVC cuff, and the more recently introduced Microcuff ETT (Kimberly-Clark, Kimberly-Clark Health Care, Roswell, Georgia), which has a polyurethane cuff. An acrylic tube (inner diameter $20 \mathrm{~mm})^{7}$ was mounted vertically, and after inserting the ETT and inflating the cuff to $20 \mathrm{~cm} \mathrm{H}_{2} \mathrm{O}$ (measured with an aneroid manometer previously tested against a water column) we poured into the acrylic mock trachea $15 \mathrm{~mL}$ of methylene-blue colored water, and measured the time needed for all the colored water to leak past the cuff, or, if there was no leak, the ETT was left in place for 24 hours. The cuffs were not lubricated before insertion. The average leakage flow was calculated as the total volume leaked, divided by the time needed for all $15 \mathrm{~mL}$ of colored water to leak past the cuff, or 24 hours if not all the colored water leaked past the cuff.

\section{Pressure Transmitted to the Tracheal Wall}

When the Lycra cuff is inflated, some of the intracuff pressure is spent to expand the Lycra. The pressure needed to expand the Lycra up to a certain diameter can be calculated from the cuff's pressure/diameter curve, which is linear in the pressure range we explored. ${ }^{6}$ The diameter of our Lycra cuff is calculated as:

Diameter at pressure $\mathrm{P}=$ at-rest diameter

$$
+ \text { diameter increase } / \mathrm{cm} \mathrm{H}_{2} \mathrm{O} \times \text { intracuff pressure }
$$

Fig. 2 shows the cuff pressure-diameter relationship. Intracuff pressure was measured with a manometer, and cuff diameter with a caliper. 


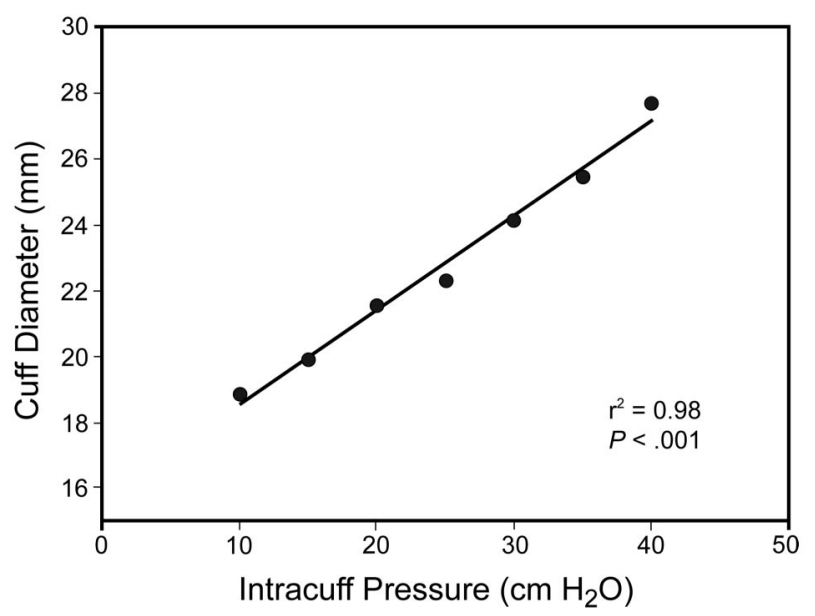

Fig. 2. Pressure-diameter relationship of our prototype Lycra endotracheal tube cuff. Diameter $=17.3 \mathrm{~mm}+(0.32 \times$ intracuff pressure). $r^{2}=0.98$. $P<.001$.

\section{Statistical Methods}

Data are expressed as mean \pm standard deviation. We classified each leakage test as with leakage or without leakage. We combined the Lycra cuff tests results with the results from the Microcuff and Hi-Lo on a $2 \times 2$ table, and analyzed the values with the Fisher exact test. We compared the absolute leakage with the Wilcoxon test only between the Hi-Lo and the Microcuff, because the leakage with the Lycra cuff showed no standard deviation. All the computations were performed with statistics software (R, R Foundation for Statistical Computing, Vienna, Austria).

\section{Results}

\section{Appearance of Inflated Lycra Cuff}

The wall thickness of the Lycra cuff was about $10 \mu \mathrm{m}$, measured with a dial micrometer. Lycra has a maximum elongation of approximately 500\% (Fig. 3), and the cuff surface was smooth and devoid of folds when inflated in the mock trachea. The Lycra cuff touched the wall of the mock trachea, leaving no gap.

\section{In Vitro Leak Test}

We observed no leakage of colored water with the Lycra cuff (Fig. 4). All the Hi-Lo cuffs had visible folds that allowed a constant trickle of colored water, with total drainage of all $15 \mathrm{~mL}$ in less than $3 \mathrm{~min}$ (average flow $1,182 \pm 1,321 \mathrm{~mL} / \mathrm{h})$. The Microcuff had smaller folds, and the leakage rate was $1.2 \pm 0.4 \mathrm{~mL} / \mathrm{h}$. The number of cuff tests with leakage was zero with the Lycra cuffs,

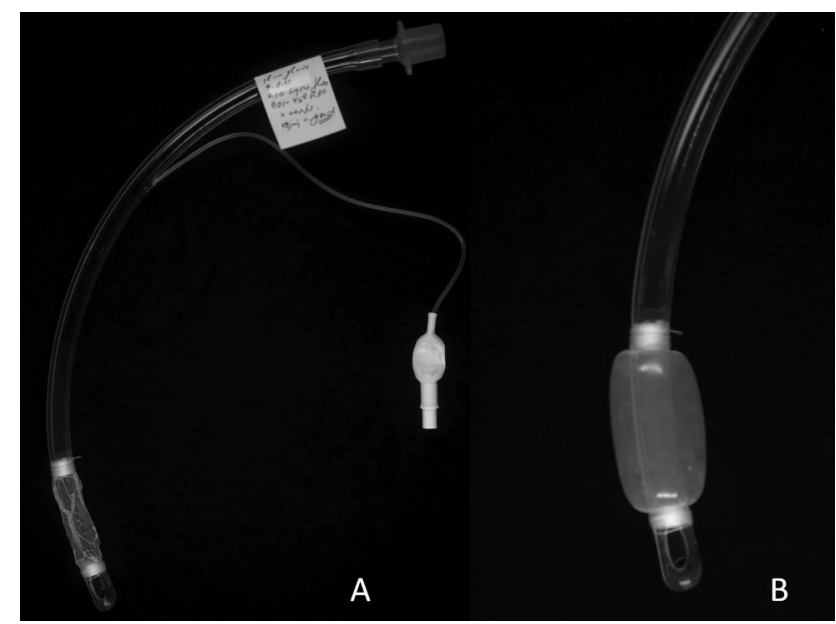

Fig. 3. Prototype Lycra endotracheal tube cuff (mounted on a Mallinkrodt, Microcuff endotracheal tube) before (A) and after (B) inflation to an intracuff pressure of $30 \mathrm{~cm} \mathrm{H}_{2} \mathrm{O}$.

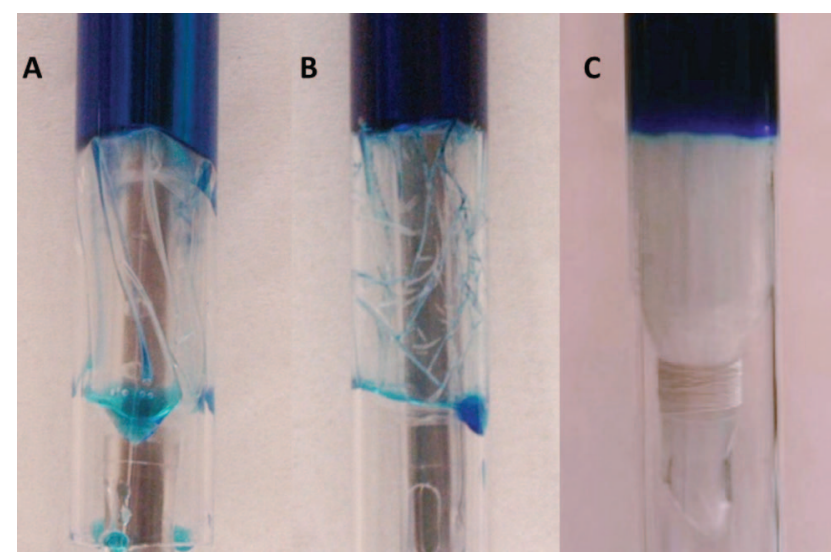

Fig. 4. Endotracheal tube cuffs inflated in the acrylic mock trachea. A: Hi-Lo. B: Microcuff. C: Prototype Lycra endotracheal tube cuff.

whereas all the Hi-Lo and Microcuff tests had leakage $(P<.001)$. Leakage with the Microcuff was significantly less than that with the Hi-Lo $(P<.001)$.

\section{Transmitted Pressure}

The diameter of the Lycra cuff increased approximately $1.4 \%$ of the at-rest diameter per $\mathrm{cm} \mathrm{H}_{2} \mathrm{O}$ of intracuff pressure added. An intracuff pressure of approximately $40 \mathrm{~cm} \mathrm{H}_{2} \mathrm{O}$ is needed to increase its diameter $77 \%$ from resting position. The at-rest diameter is $17.3 \mathrm{~mm}$, which is slightly less than the glass rod on which the Lycra cuff is manufactured (18 $\mathrm{mm})$, probably owing to drying contraction.

\section{Discussion}

Our in vitro results suggest that our low-pressure Lycra cuff can seal the trachea without cuff folds. The commer- 
cially available PVC and polyurethane cuffs are almost inelastic and form folds. Absence of folds completely prevents fluid leakage past the cuff, as demonstrated by Young et al, who developed a commercially available thick silicon cuff, ${ }^{8}$ which, however, requires a high inflation pressure, and by Zanella et al, who developed a prototype double-layer Guayule latex cuff, which is not yet commercially available. ${ }^{9}$

Our choice of Lycra was based on our previous experience, Lycra's exceptional elongation, and its resistance to deterioration: some Lycra catheters made 30 years ago still look new. ${ }^{5}$ We developed technology and know-how to fabricate Lycra (and other polymers with high elongation) ETT cuffs that are highly elastic and we believe may improve the care of intubated mechanically ventilated patients.

The present prototype, developed in our laboratory, ensures a perfect seal with a low intracuff pressure if the cuff's resting diameter is close to the diameter of the trachea; if the difference between the cuff's resting diameter and the trachea diameter is greater, higher intracuff pressure is needed because an increased percentage of the intracuff pressure is spent on distending the cuff.

We did not perform a thorough comparison between our cuff and other commercially available ETT cuffs. Our tests were performed at one pressure and one trachea diameter, to test a concept that we believe is fundamental: folds, no matter how small, are invariably associated with possible leakage. The Microcuff design was based on the principle of the traditional high-volume low-pressure cuff: the cuff was meant to be larger than the trachea ${ }^{3}$; the ultra-thin polyurethane makes the folds very small, which decreased but did not eliminate leakage in our study. ${ }^{9}$

Subglottic secretions are more viscous than water and therefore flow through narrow folds slower than water, so our choice of water may have biased our results against the Hi-Lo and Microcuff, resulting in a leakage of $1,182 \pm 1,321 \mathrm{~mL} / \mathrm{h}$ with the Hi-Lo, which is not observed clinically. Another possible bias is that a human trachea is neither cylindrical nor rigid, so our results cannot immediately be transferred to clinical practice The lack of water leakage we observed for 24 hours may not reflect clinical performance, since in our setup the mock trachea and ETT remained still, whereas in vivo the cuff moves inside the trachea when the patient's neck bends. ${ }^{10}$

Though Lycra is highly distensible, it needs some pressure to be inflated and stretched (about $40 \mathrm{~cm} \mathrm{H}_{2} \mathrm{O}$ to obtain a diameter 1.8 times the baseline); part of the intracuff pressure is spent to keep the cuff inflated and part is spent on the tracheal wall, depending on the size of the trachea. When the Lycra cuff is inflated in a trachea with a diameter close to the diameter of the cuff, the transmitted pressure is about $5 \mathrm{~cm} \mathrm{H}_{2} \mathrm{O}$ lower than the intracuff pressure, but with a trachea $5 \mathrm{~mm}$ wider the difference be- tween intracuff pressure and transmitted pressure reaches $15 \mathrm{~cm} \mathrm{H}_{2} \mathrm{O}$.

Young and Blunt proposed a thick cuff devoid of folds, ${ }^{11}$ which they achieved by inflating the cuff with fixed volume and relying upon the saturation of the shape of the pressure-volume curve beyond a certain pressure value. But that pressure is quite high $\left(>70 \mathrm{~cm} \mathrm{H}_{2} \mathrm{O}\right)$. Our Lycra cuff's pressure-volume curve is linear (see Fig. 2) and its slope remains constant, even at low intracuff pressures.

Epidemiologic studies suggest that bacteria are derived from the oropharynx and from the gut, and are responsible for ventilator-associated pneumonia (VAP). ${ }^{12,13}$ Early-onset VAP seems mostly derived from Gram-positive oral bacteria, whereas late-onset VAP is from multi-resistant Gram-negative bacteria from the gut. ${ }^{12,14}$ Some bacteria enter the trachea during intubation, but it is reasonable to assume that the bulk of bacteria that cause VAP come from leakage of subglottic secretions past the ETT cuff. Such leakage has also been proven through the finding of pepsin in tracheal secretions. ${ }^{14}$ It is reasonable to assume that a cuff with no leak would reduce the incidence of VAP. Indirect confirmation of that concept comes from studies on continuous suctioning of subglottic secretions, which found a reduced incidence of VAP, though continuous suctioning is also injurious to tracheal mucosa. ${ }^{15,16}$ Moreover, recent clinical studies of the Microcuff found a reduced incidence of VAP, which is plausible to associate with reduced cuff leakage. ${ }^{17,18}$

\section{Conclusions}

The substantial risks associated with cuff leakage merit the trial of new technology to prevent cuff leakage and thus improve patient outcomes and lower costs by decreasing the incidence of VAP. In this preliminary bench study we found that our smooth, highly distensible Lycra cuff performed better than Hi-Lo or Microcuff in vitro. Clinical studies of the Lycra cuff are warranted.

\section{ACKNOWLEDGMENTS}

We thank Angelo Colombo MD for statistical advice.

\section{REFERENCES}

1. Cooper JD, Grillo HC. Experimental production and prevention of injury due to cuffed tracheal tubes. Surg Gynecol Obstet 1969;129(6): 1235-1241.

2. Young PJ, Rollinson M, Downward G, Henderson S. Leakage of fluid past the tracheal tube cuff in a benchtop model. Br J Anaesth 1997;78(5):557-562.

3. Dullenkopf A, Gerber A, Weiss M. Fluid leakage past tracheal tube cuffs: evaluation of the new Microcuff endotracheal tube. Intensive Care Med 2003;29(10):1849-1853.

4. Bauer TT, Ferrer R, Angrill J, Schultze-Werninghaus G, Torres A. Ventilator-associated pneumonia: incidence, risk factors, and microbiology. Semin Respir Infect 2000;15(4):272-279. 


\section{Prototype Lycra Endotracheal Tube Cuff Versus Hi-Lo and Microcuff}

5. Kolobow T, Zapol W. A new thin-walled nonkinking catheter for peripheral vascular cannulation. Surgery 1970;68(4):625-629.

6. Kolobow T, Tsuno K, Rossi N, Aprigliano M. Design and development of ultrathin-walled, nonkinking endotracheal tubes of a new "no-pressure" laryngeal seal design. A preliminary report. Anesthesiology 1994;81(4):1061-1067.

7. Chandler M, Crawley BE. Rationalization of the selection of tracheal tubes. Br J Anaesth 1986;58(1):111-116.

8. Young PJ, Burchett K, Harvey I, Blunt MC. The prevention of pulmonary aspiration with control of tracheal wall pressure using a silicone cuff. Anaesth Intensive Care 2000;28(6):660-665.

9. Zanella A, Cressoni M, Epp M, Stylianou M, Kolobow T. A doublelayer tracheal tube cuff designed to prevent leakage: a bench-top study. Intensive Care Med 2008;34(6):1145-1149.

10. Young PJ, Basson C, Hamilton D, Ridley SA. Prevention of tracheal aspiration using the pressure-limited tracheal tube cuff. Anaesthesia 1999;54(6):559-563.

11. Young PJ, Blunt MC. Improving the shape and compliance characteristics of a high-volume, low-pressure cuff improves tracheal seal. Br J Anaesth 1999;83(6):887-889.

12. Johanson WG Jr, Pierce AK, Sanford JP, Thomas GD. Nosocomial respiratory infections with gram-negative bacilli. The significance of colonization of the respiratory tract. Ann Intern Med 1972;77(5): 701-706.
13. Torres A, el Ebiary M, González J, Ferrer M, Puig de la Bellacasa J, Gené A, et al. Gastric and pharyngeal flora in nosocomial pneumonia acquired during mechanical ventilation. Am Rev Respir Dis 1993; 148(2):352-357.

14. Torres A, Serra-Batlles J, Ros E, Piera C, Puig de la Bellacasa J, Cobos A, et al. Pulmonary aspiration of gastric contents in patients receiving mechanical ventilation: the effect of body position. Ann Intern Med 1992;116(7):540-543.

15. Berra L, Panigada M, De Marchi L, Greco G, Xi Y, Baccarelli A, et al. New approaches for the prevention of airway infection in ventilated patients. Lessons learned from laboratory animal studies at the National Institutes of Health. Minerva Anestesiol 2003;69(5):342-347.

16. Berra L, De Marchi L, Panigada M, Yu ZX, Baccarelli A, Kolobow T. Evaluation of continuous aspiration of subglottic secretion in an in vivo study. Crit Care Med 2004;32(10):2071-2078.

17. Duguet A, D'Amico L, Biondi G, Prodanovic H, Gonzalez-Bermejo J, Similowski T. Control of tracheal cuff pressure: a pilot study using a pneumatic device. Intensive Care Med 2007;33(1): $128-132$

18. Lorente L, Lecuona M, Jimenez A, Mora ML, Sierra A. Influence of an endotracheal tube with polyurethane cuff and subglottic secretion drainage on pneumonia. Am J Respir Crit Care Med 2007;176(11):1079-1083.

This article is approved for Continuing Respiratory Care Education credit. For information and to obtain your CRCE

(free to AARC members) visit www.RCJournal.com 